NEWS

\title{
Claims of brain drain follow CDC reshuffle
}

Preventing disease has always lacked the prestige of curing it. Now advocates for public health are concerned that the field is being further undermined by dissent behind the doors of the US Centers for Disease Control and Prevention (CDC), one of the world's highest-profile public-health agencies. And many fear that if the United States is faced with a health crisis - an outbreak of pandemic flu, say, or the next SARS - the cracks will become chasms.

The federal agency, which works to combat outbreaks of infectious disease and chronic conditions such as diabetes, has seen discontent grow in the past few years over a lengthy reorganization. Concerns resurfaced earlier this month after the Atlanta Journal-Constitution revealed that five former CDC directors had sent a letter of concern about staff morale to the agency's director, Julie Gerberding, last December. The article sparked a record 90,000 hits and a flurry of discussion on a blog that discusses CDC internal affairs (www.cdcchatter.net) and in wider public-health circles. According to a crude poll on the site, $82 \%$ of voters agreed that the newspaper article accurately reflected the situation at the agency.

Established 60 years ago, the CDC has long been known for its expertise in investigating infectious outbreaks. But after the anthrax attacks of autumn 2001, many acknowledged that the agency needed a shake-up because its 11 national centres of expertise lacked coordination, communication and efficiency.

Gerberding launched her reorganization, called the Futures Initiative, in June 2003, a year after taking office. Complaints soon began when some employees felt they were being sucked into multiple, officious committees. And when the new structure was announced in spring 2004, some were dismayed at the introduction of four coordinating centres that, critics say, created an extra layer of management between scientists and the director and stripped senior scientists of control over their budgets.

Many CDC employees are reluctant to talk openly about their concerns - and publichealth experts outside the agency are also reticent because they are often closely linked with, or receive money from, the agency.

But privately, CDC employees say they are demoralized by the reorganization because it has introduced extra bureaucracy, lowered the status of science and placed too much emphasis on 'spin'. They say these changes, and the new corporate management style, are ill-suited to an agency that is supposed to investigate and

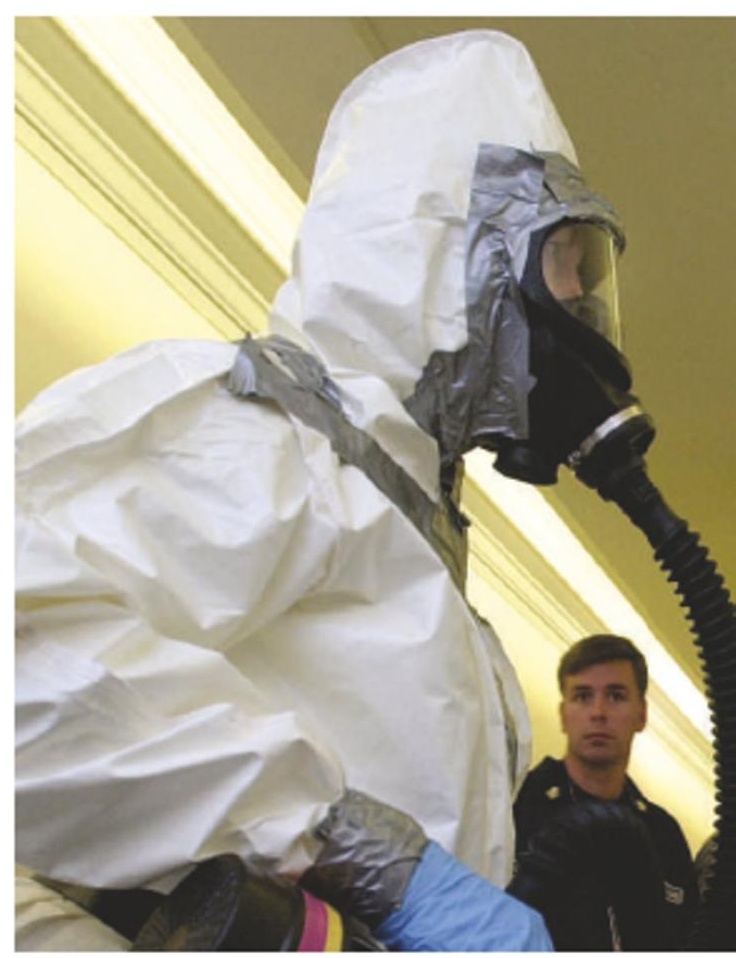

Some scientists are concer ned that the US is being left poorly prepared for a health crisis.

protect public health. ${ }^{\alpha}$ The message from the current leadership is that the important scientific issues are decided elsewhere; we just have to look good to the media and not challenge conventional wisdom," says one senior publichealth researcher at the CDC.

The sour situation is thought to be one reason behind a wave of high-level departures:

\section{Health agency backs use of DDT against malaria}

After decades of being shunned as an environmentally damaging chemical, the pesticide DDT is once again being touted as the most effective way to fight malaria.

The World Health Organization (WHO) announced on 15 September that it will support the indoor spraying of pesticides generally, and DDT specifically, to control mosquitoes in countries with high rates of malaria. The USAgency for International Development signalled a similar shift in policy back in May.

Although these agencies never formally opposed DDT, they did not fund countries to purchase it, and instead actively promoted the use of insecticide-treated bednets. Malaria rates have continued to rise in the meantime, claiming more than a million lives a year, mostly in sub-Saharan Africa. The agencies now advocate combining the two approaches.

"I have to pinch myself a little to believe that they've done this, but I'm really, really happy they have," says Amir Attaran, professor of law and medicine at the University of Ottawa, Canada, who has long criticized the agencies for their malaria policies.

In sharp contrast to its previous stance, the WHO also admitted for the first time that it stopped supporting DDT despite evidence of its effectiveness. "There are lots of data there, but peopleare soemotional about the issues," says Arata Kochi, director of the WHO's Global Malaria Programme. "Science comes first and we must take a position based on the science and the data."

DDT, or dichlorodiphenyltrichloroethane, is an organochlorine that is more effective, cheaper and longerlasting than the alternatives. Fears about its use date back to the 1960 s when Rachel Carson's book, Silent Spring, famously chronicled its devastating effects on the environment. In the years that followed, the United States and many European countries banned DDT.

These countries once used thousands of tonnes of the pesticide for agricultural purposes. But the use of DDT for malaria control is very different: small quantities are sprayed once or twice a year on the inside walls and ceilings of houses. Following widely publicized success with DDT in some countries such as India and South Africa, others began clamouring for the pesticide. "A lot of countries, especially in southern Africa, have become bullish about the use of DDT," says Richard Tren of the non-profit group Africa Fighting Malaria. 


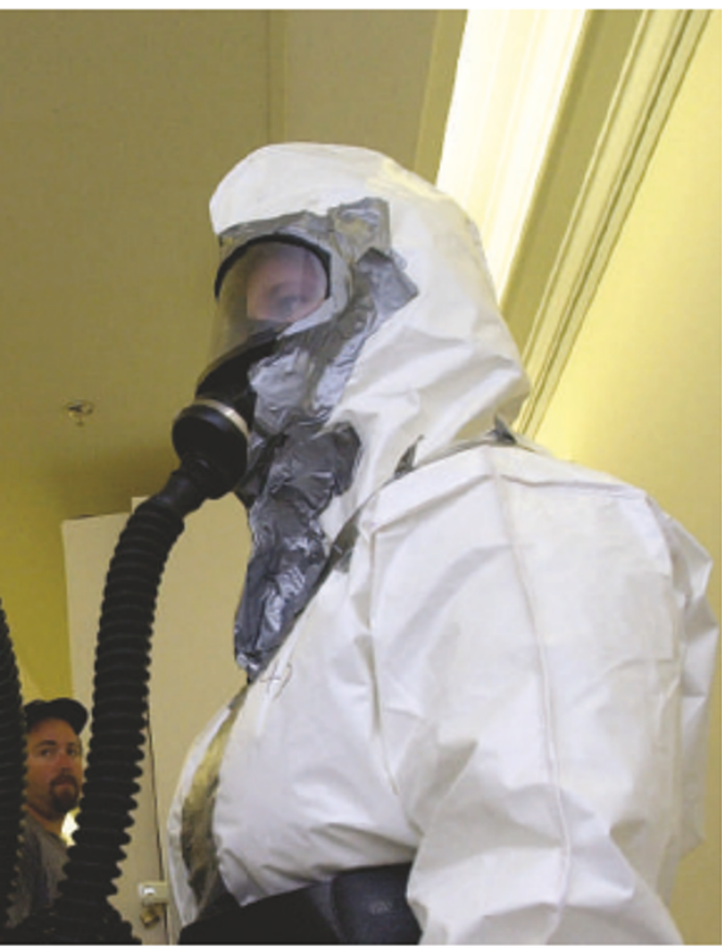

a at least eight directors of the former national centres of expertise have left since 2004. The s repercussions are being felt both nationally $\checkmark$ and internationally, because the CDC plays a central role in coordinating public health across state and local health departments, as well as international responses to emerging infectious diseases. "Most people in public health are very concerned to see this level of a brain drain in the CDC, says Jeffrey Levi, head of Trust for America's Health, a non- profit organization based in Washington DC that works to promote disease prevention.

Observers lay some of the blame on the Bush administration, which they say encouraged the agency to focus on preparation for bioterrorism at the expense of other needs. "All the emphasis was on terrorism, without willingness to recognize that the public-health infrastructure has been getting weaker for years," says Anthony Robbins, a professor of public health at Tufts University in Boston. In the 2006 financial year, the CDC received funding boosts for bioterror and pandemic-flu planning while many chronic-disease prevention programmes were cut.

The accusation that politics
"You can't manage a place where people don't trust you."
Freeman, who specializes in public-health policy at the University of Massachusetts, Boston.

But CDC spokesman Tom Skinner says that "there is no merit whatsoever" in the argument that the agency cannot protect publichealth. $\mathrm{He}$ says most employees understand that the agency needs to change and they have been thoroughly involved in the process. He adds that Gerberding and the agency's executive management are aware that some employees are unhappy with the reorganization and that, starting later this month, two people will be hired as ombudsmen to deal with some of their concerns. Gerberding was not available for comment.

Critics offer no clear solution is usurping science has also reared its head. Critics say pressure from the administration stops the agency from investigating pressing public-health issues, such as whether abstinence-only programmes work in the fight against HIV or whether junk food is fuelling the obesity epidemic. "There is not a feeling that science drives the agenda," says a senior official who left the CDC more than five years ago. Others are critical of Gerberding herself for not resisting these political pressures and fighting for the agency's agenda.

The fear now is for what would happen if the country had to deal with a public-health crisis. Many in the field draw parallels between the $\mathrm{CDC}$ and the Federal Emergency Management Agency, the organization so heavily criticized over its inadequate response to Hurricane Katrina. "Our preparedness has been deteriorating in fairly dramatic and drastic ways," says Phyllis for the CDC's woes, although some want Gerberding replaced with a stronger advocate for public health. "You can't manage a place where people don't trust you," says one CDC employee. Robbins says he hopes to propose a 'strike fund' for publichealth workers who want to speak out about their concerns - to cover wages or legal costs for anyone who loses their job as a result.

Troubles at the CDC are symptomatic of the persistently low profile that the United States gives to public health, a field that is sometimes sidelined politically and financially when compared with research in new drugs. (Test: do you know who the US surgeon-general is?) The CDC loses out politically because it is based in Atlanta, Georgia, rather than Washington DC. And, according to Freeman, it ${ }^{\alpha}$ is pitiful in its ability to draw attention and bring funding "compared with the National Institutes of Health.

Helen Pearson

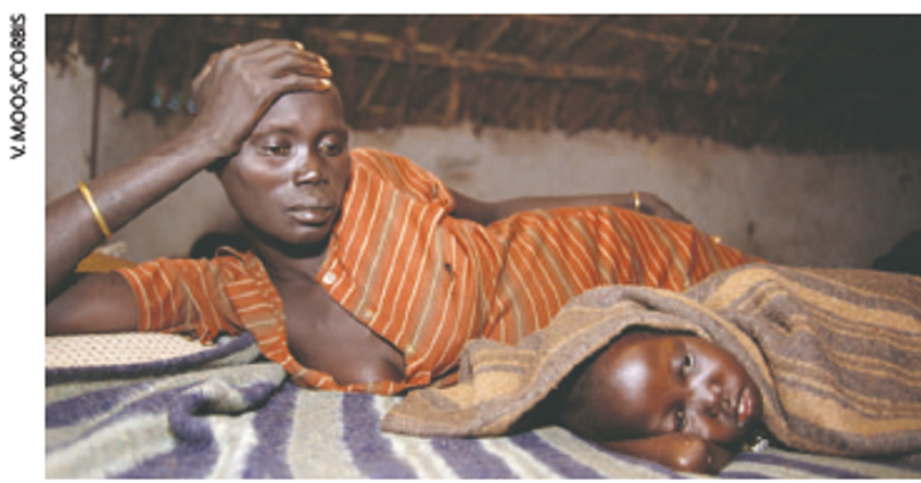

More than a millionlives are lost to malaria each year.

Even environmental groups that once vehemently opposed DDT recognize its value in malaria control. "We still think that DDT is trouble," says Ed Hopkins, director of the environmental quality programme at the Sierra Club, a conservation group based in San Francisco." Butin some situations, where there are no alternatives, the well controlled use of DDT is better than having millions of people die from malaria."

Other groupssay they are concerned that the agencies are not dedicating enough resources to developinglonger-term alternatives to DDT. "DDT is a short-sighted response withlong-term consequences," says Paul Saoke, director of Physicians for Social Responsibility in Kenya.

Before countries can begin using DDT, the WHO must map resistance to pesticides to determine where spraying is likely to be effective and which pesticide would be best. Spraying won't work where mosquitoes bite and rest outdoors. And in most cases, mosquitoes - and with them, malaria - will return as soon as spraying stops, so the programmes require long-term commitment from both governments and donors. But these practical hurdles can be tackled, says Kochi. "So many people took the position that even though DDT and indoor residual spraying are effective, it cannot be sustained," he says. "My sense is, nothing is sustain able unless you decide to make it so. People make excuses."

Kochi, who also set up the Stop TB Initiative, is largely credited with the changes in the WHO's approach. Shortly after he took this job in October 2005, he demanded that pharmaceutical companies stop marketing single-drug artem isinin medicines, and only sell combination drugs, in order to prevent resistance.

"The breath of freshair this man represents is just tremendous," says Attaran. "He's perfect for this job." Apoorva Mandavilli 